\title{
Chicken Anatomical Composition Prediction in Madagascar: Indigenous Race and Starbro Strain
}

\author{
Isabelle Herisoa Hantanirina ${ }^{1}$, Rivo Nirina Rabearimisa ${ }^{1}$, Jean de Neupomuscène Rakotozandriny ${ }^{1}$ and Claude \\ Mazel $^{2}$ \\ 1. Department of Animal Science, Graduate School of Agronomics Sciences, University of Antananarivo, Antananarivo 175, \\ Madagascar \\ 2. Modeling and Optimization Systems Laboratory, Blaise Pascal University/CNRS, Clermont-Ferrand II, Campus Cézeaux 10125, \\ France
}

\begin{abstract}
Consumer requirement evolution in time necessitates a good control on product features. The present study aims at providing a better knowledge about the different broiler body composition characteristics found in Madagascar poultry farms. Data about 8,262 heads of indigenous race or Starbro strain chickens, raised in a suburban setting have been collected. At the end of the raising cycle, measurements by individual weighing of the animal anatomical composition were performed. The results showed that chicken live weight variation depends upon liver, thigh, wing, breast and abdominal fat weight variation. Chicken age at slaughtering doesn't have any effect on the variable. The derived multilinear regressions make up relevant simulations on observed data due to their significance $\left(\mathrm{p}<1 \%\right.$ ) and present some satisfactory statistical estimate indices, especially with a steady adjusted $\mathrm{R}^{2}$ value.
\end{abstract}

Key words: Poultry indigenous race, Starbro broiler strain, anatomical composition, prediction model, Madagascar.

\section{Introduction}

Poultry farming is one of the oldest activities allowing man to provide for his daily needs and constituting for him one of the most appreciated protein source. Since 2007, world meat consumption didn't stop increasing in spite of all the food crises, especially white meat consumption, after three years of very low level of consumption. Demand in poultry meat went up especially that of broiler, in proportions often related to the population level of income but also to each and every country social and cultural factors [1-3]. So, farmers, whose goal would be obtaining maximum production, would end up with offers over exceeding demands on the market. In the same way, consumers became more and more quality conscious on the proposed products. Cultural trends exerted their influences, not only on food quality, but also on

Corresponding author: Isabelle Herisoa Hantanirina, senior lecturer, research field: livestock production. animal well-being, environment preservation, biodiversity maintenance and sustainable development. This was how on the poultry market, a huge offer segmentation has been noted lately with important progresses for cut products and transformed products [4-6]. Such a development and such a market evolution required a better control over product features, and in the present case, over the poultry product physical quality. However, in Madagascar, poultry farming is mostly practiced in a traditional manner with the chicken indigenous race, in spite of the rapid growth of modern poultry production observed in suburban areas [7-9]. For the sake of offering quality products to consumers, this study aims to propose a tool that would help estimating the ratios of the different pieces of cut of chicken upon animal live weight while trying to assess the main relationships that may exist between chicken live weight and weights of the different pieces of cut. 


\section{Material and Methods}

\subsection{Material}

The data were simultaneously collected from different poultry farms located in the suburb of Antananarivo city and from different slaughtering facilities of the city between November 2006 and April 2007. A total of 8,262 heads of chickens were taken into consideration, comprising 1,309 individuals of the indigenous race and 6,953 chickens of the Starbro strain. Chickens of the indigenous race were raised in extensive way while being fed a supplement at the end of the day, whereas, Starbro strain chickens, raised in a more intensive manner, received a well balanced ration distributed twice a day. The farmers took themselves charge of the sanitary follow-up all along the raising cycle. The length of the raising cycle varied from 40 days to 61 days for the Starbro strain chicken versus 100 days to 186 days for the indigenous race. A kitchen scale presenting a $3 \mathrm{~kg}$ range and $1 \mathrm{~g}$ of precision was used to weigh individual chicken before slaughtering as well as pieces of cuts after slaughter. The JMP/SAS 5.0.1 software was used for data treatment.

\subsection{Methods}

In a general manner, chickens are slaughtered the very same day they are sold on the market or at most the day before in the evening in case of a larger demand. For the latter, carcasses are frozen during the whole night preceding the sale. The animal live weight before slaughtering (PV) as well as weights of the carcass various parts such as Thigh (PC), Wing (PA), Breast (PB), Liver (PF) and Abdominal Fat (PGA) are measured by weighing the animals individually.

Multiple linear regression method is used to develop a prediction model of live weight depending on the weights of the various carcass parts and the animal age at slaughter (AA) $[10,11]$ using the Eq. (1):

$$
\begin{gathered}
P V=a+b_{1}(P C)+b_{2}(P A)+b_{3}(P B)+b_{4}(P F) \\
+b_{5}(P G A)+b_{6}(A A)
\end{gathered}
$$

Thus, five statistical indicators have been used to assess the resulting models: (1) the least square standard error $(\sigma)$ : the smaller this variable the better is the simulation model precision $[12,13]$; (2) the coefficient of determination $\left(\mathrm{R}^{2}\right)$ that measures the proportion of the total live weight variation explained by the variations of the independent variables (piece of cut weights and age at slaughtering). The greater the coefficient the better the linear model explains the observed data. The coefficient value also indicates the existence of relationships between the explained variable and independent variables [14-16]; (3) the adjusted coefficient of determination (adjusted $\mathrm{R}^{2}$ ) allows to identify the optimum number of explaining variables within the equation linear model Eq. (2):

$$
R_{\mathrm{aj}}^{2}=1-\frac{\left(1-R^{2}\right)(n-1)}{n-m-1}
$$

Where, $n$ is the number of observations and $m$ is the numbers of independent or explaining variables in the model not including the intercept; (4) the Error Ratio Geometric Mean (MGRE) to test the predicted value bias within Eq. (3):

$$
\operatorname{MGRE}=\operatorname{Exp}\left[\frac{1}{n} \sum_{i=1}^{n} \ln \varepsilon_{i}\right]
$$

and (5) the Error Ratio Geometric Standard Deviation (ETGRE) that allows to assess the level of noise introduced within the model by Eq. (4):

$$
\mathrm{ETGRE}=\operatorname{Exp}\left[\sqrt{\frac{1}{n-1} \sum_{i=1}^{n}\left(\ln \varepsilon_{i}-\ln \mathrm{MGRE}\right)^{2}}\right]
$$

Where, $\mathrm{n}$ is the number of observations and $\varepsilon_{\mathrm{i}}$ is ratios between the model predicted values and the corresponding observed values.

The regression equation determination coefficient $\left(\mathrm{R}^{2}\right)$ could increase up to a value of 1 while the adjusted $\mathrm{R}^{2}$ coefficient is going to stay constant at a 
given value if the number of independent variables are great enough to explain all the data and, therefore, to set up the model $[17,18]$.

A MGRE value greater than 1 means an overestimation from the model, whereas it means a model underestimation if this value is too small. On the other hand, the ETGRE value is always greater than or at least equal to 1 . A value significantly greater than 1 indicates that the model predicted variables show too big a difference compared to measured data. Values of MGRE and ETGRE equal to 1 correspond to a perfect fit between the model predicted values and measured data. Thus, the model is particularly reliable as it shows a MGRE value close to 1 and a low ETGRE value [19].

Therefore, a significant model presenting satisfying values over the five statistical indicators presented above could be considered suitable and appropriate enough for predicting and/or simulating poultry meat production at cutting.

\section{Results and Discussion}

Regression equations with 3-6 variables have been developed in order to more and more minimize residual variances and get as reliable a model as possible. Synthetics summary of the developed models were presented in Tables 1 and 2 .

Among chickens of the Indigenous Race, associating thigh, wing and breast weights (Table 1, 1a) explains $95.28 \%$ of the chicken live weight variation. The model is significant $(p<1 \%)$ for an adjusted determination coefficient of $95.27 \%$. Yet, the two statistical parameters, ETGRE and MGRE, presenting values of 1.0343 and 1.000385, respectively, indicate that the model tends to overestimate the measured data.

The same inference could be drawn from the model set up for Starbro strain chicken sample (Table 2, 5b). The model with 3 variables is significant $(\mathrm{p}<1 \%$ ) with an adjusted determination coefficient of $93.86 \%$ and statistical parameters ETGRE and MGRE values of, respectively, 1.0398 and 1.000549 .

An apparent stability of the adjusted determination coefficient has been noted with the 4 variable models that associate weights of the different chicken pieces of cut, while permuting the liver weight with that of the abdominal fat as the fourth variables.

Among the indigenous race chicken (Table 1, 2a and $3 \mathrm{a}$ ), the adjusted determination coefficient for the model having liver weight as the fourth factor is

Table 1 Indigenous race chicken prediction equation model characteristics $(n=1,309)$.

\begin{tabular}{|c|c|c|c|c|c|}
\hline $\mathrm{N}$ & Prediction equations & $\begin{array}{l}\text { Standard } \\
\text { deviation }\end{array}$ & $\begin{array}{l}\text { Adjusted } \\
\mathrm{R}^{2}\end{array}$ & ETGRE & MGRE \\
\hline 1a & $P V=135.6+2.301(P C)+2.237(P A)+1.470(P B)$ & 45.878 & 0.9527 & 1.0343 & 1.0003850 .9528 \\
\hline $2 \mathrm{a}$ & $P V=105.8+2.071(P C)+2.045(P A)+1.324(P B)+4.114(P F)$ & 40.756 & 0.9627 & 1.0308 & 1.0003430 .9628 \\
\hline $3 a$ & $P V=149.1+2.209(P C)+2.319(P A)+1.367(P B)+1.378(P G A)$ & 44.787 & 0.9549 & 1.0334 & 1.0003840 .9551 \\
\hline $4 \mathrm{a}$ & $\begin{array}{c}P V=116.8+2.020(P C)+2.111(P A)+1.262(P B)+3.902(P F) \\
+0.943(P G A)\end{array}$ & 40.204 & 0.9637 & 1.0303 & 1.0003440 .9638 \\
\hline $5 a$ & $\begin{array}{c}P V=117.7+2.020(P C)+2.110(P A)+1.262(P B)+3.903(P F) \\
+0.943(P G A)-0.006(A A)\end{array}$ & 40.219 & 0.9637 & 1.0303 & 1.0003440 .9638 \\
\hline
\end{tabular}

Table 2 Starbro strain chicken prediction equation model characteristics $(n=6,953)$.

\begin{tabular}{|c|c|c|c|c|c|c|}
\hline $\mathrm{N}$ & Prediction equations & $\begin{array}{l}\text { Standard } \\
\text { deviation }\end{array}$ & $\begin{array}{l}\text { Adjusted } \\
\mathrm{R}^{2}\end{array}$ & ETGRE & MGRE & $\mathrm{R}^{2}$ \\
\hline $\mathrm{b}$ & $P V=139.4+2.484(P C)+1.714(P A)+1.494(P B)$ & 53.757 & 0.9386 & 1.0398 & 1.000549 & 0.9386 \\
\hline $2 b$ & $P V=113.6+2.318(P C)+1.485(P A)+1.386(P B)+3.417(P F)$ & 51.023 & 0.9447 & 1.0376 & 1.000522 & 0.9447 \\
\hline $3 b$ & $P V=128.9+2.352(P C)+1.825(P A)+1.358(P B)+1.895(P G A)$ & 51.78 & 0.943 & 1.0384 & 1.00053 & 0.943 \\
\hline $4 \mathrm{~b}$ & $\begin{array}{c}P V=132.8+2.219(P C)+1.602(P A)+1.278(P B)+3.099(P F) \\
+1.641(P G A)\end{array}$ & 49.49 & 0.9479 & 1.0365 & 1.000509 & 0.948 \\
\hline $5 b$ & $\begin{array}{c}P V=135.9+2.221(P C)+1.601(P A)+1.279(P B)+3.099(P F) \\
+1.641(P G A)-0.066(A A)\end{array}$ & 49.493 & 0.9479 & 1.2801 & 1.000512 & 0.948 \\
\hline
\end{tabular}


$96.27 \%$, a value decreasing to $95.49 \%$ if abdominal fat weight is used instead. Whereas, the statistical parameter ETGRE would increase from 1.0308 to 1.0334, respectively for liver weight and abdominal fat weight, and the parameter MGRE also would increase from 1.000343 for liver weight to 1.000384 for abdominal fat weight.

Among the Starbro strain chicken (Table 2, $2 \mathrm{~b}$ and $3 b$ ), some similar situations have been met showing an increase in the value of the statistical parameters, from 1.0376 to 1.0384 for ETGRE, and from 1.000522 to 1.000530 for MGRE with an adjusted determination coefficient varying from $94.47 \%$ down to $94.30 \%$.

Equations with 5 factors associating together the weights of the different pieces of cut show an adjusted determination coefficient of $96.37 \%$ for the indigenous race (Table 1, 4a) and of $94.79 \%$ for the Starbro strain (Table 2, 4b). Both coefficients show that accounted for variables represent chicken live weight variation in an optimal way, a significant relationship exists $(p<1 \%)$ between live weight and the set of weight for the different pieces of cut $\left(\mathrm{R}^{2}=\right.$ 0.964 for the indigenous race and $R^{2}=0.948$ for the Starbro strain). The statistical parameters show a good fit between measured data and predicted values with an ETGRE of 1.0303 for the indigenous race, 1.0365 for the Starbro strain, a MGRE value of 1.000344 for the indigenous race and a value of 1.000509 for the Starbro strain. These MGRE values, very close to 1 , associated to low ETGRE values could be considered to be very satisfactory $[17,18,20,21]$.

Variable age at slaughtering (AA) integration as a sixth variable within the model has given significant predicting equations $(\mathrm{p}<1 \% \mathrm{~m})$ and an accurate steadiness of the adjusted determination coefficient: $96.37 \%$ for the indigenous race (Table 1, 5a) and $94.79 \%$ for the Starbro strain (Table 1, 5b). Chicken live weight variation would be explained up until $96.38 \%$ for the indigenous race sample, and up to $94.80 \%$ for the Starbro strain sample. Despite all that, for the Starbro strain, a higher value of ETGRE (1.280) tends to skew the predicted values $[17,18,20,21]$. Chicken age at slaughtering doesn't have a great influence on the chicken anatomical composition prediction, even more as the associated regression coefficient is very low $(-0.006$ for the indigenous race and -0.066 for the Starbro strain) and non significant $(\mathrm{p}=0.9234$ for the indigenous race and $\mathrm{p}=0.6508$ for the Starbro strain) [22-24].

In spite of an adjusted $\mathrm{R}^{2}$ coefficient (0.9479) steadiness noted through models with five or six variables (Table 2, 4b and 5b), an ETGRE coefficient (1.280) high value, as well as a low regression coefficient (-0.066) along with the variable age at slaughtering allow to consider the five variable model (Table 2, 4b) to be more accurate than the other prediction models set up for Starbro strain chicken [17, $18,22,23,25]$. Therefore, chicken age at slaughtering decreases the efficiency of the regression equation for Starbro strain $($ ETGRE $=1.280)$ which comes to adding a non significant random variable to the model [21]. Thus, it could be inferred that the five considered variables (thigh weight, wing weight, breast weight, liver weight and abdominal fat weight) effectively contribute to the live weight prediction of chicken either for fast growing or for slow growing strain [17, 18, 20, 24-26].

In practice, non linear models such as the Logarithmic model $\left(\mathrm{R}^{2}=0.9952\right.$ for hen and $\mathrm{R}^{2}=$ 0.9963 for rooster), the Gomperts model $\left(\mathrm{R}^{2}=0.9986\right.$ and $\mathrm{R}^{2}=0.9990$, respectively for hen and for rooster) and the Bertalanffy model $\left(\mathrm{R}^{2}=0.9991\right.$ for the rooster and $\mathrm{R}^{2}=0.9993$ for the hen) are more used in biology prediction equation due to their accuracy [27-34]. Besides, multivariate linear equations could also be used within the field of prediction. Certainly, they are less accurate than non linear models but they are able to explain in a more precise manner the different biological relationships integrated within the model $\left(\mathrm{R}^{2}=0.826\right.$ with an adjusted $\mathrm{R}^{2}$ greater than 0.794 for chicken egg production) [35], $\left(\mathrm{R}^{2}=0.3186\right.$ with adjusted $R^{2}=0.540$ for the Japanese quail) [36-39]. 
In general, among birds, abdominal fat as well as all adipose tissues development could exert an influence over the weight growth of the other pieces of cut, whatever may be the strain being considered. The correlation between live weight, liver weight and abdominal fat weight results from the studied strain adipose tissue potential for growth, as for example, with young quails raised in aviary or in confinement [40]. In the same way, roosters and capons, for which there is a significant growth of adipose tissues and subcutaneous fat, show a close relationship between carcass weight and abdominal fat weight $(\mathrm{R}=0.79)$ [41]. Females, in particular, compared to males tend to show a greater abdominal fat development within a shorter period of time that is explained by the fact, for females, hepatic activity (in fact, liver fat synthesis) is in favor of fat metabolism, leading afterward to abdominal fat deposit [42-44]. In agreement with these results, this study allowed to find that fast and precocious liver development $(157.23 \%$ of growth during the first week of life versus $131.2 \%$ for live weight) favors an abdominal fat growth, greatly remarkable for fast growing individuals [45].

\section{Conclusions}

The five variable regression equations would be the best chicken anatomical composition prediction model. Live weight variation is therefore in close relationship with the main piece of cut (thigh, wing and breast) weight variations, and on a lesser level, with liver and abdominal fat weights. Broiler meat quantity assessment is based upon the knowledge of the bird muscular development process. By using the multiple linear regression method, it is possible to predict this production with a 5 variable linear equation: chicken live weight variation is dependent upon liver, thigh, wing, breast and abdominal fat weight variation, while chicken age at slaughtering doesn't have any effect on the variable. Finally, the defined regression equations include several features related to chicken growth physiology and will allow considering in the future different improvements on poultry production practices on farms.

\section{Acknowledgments}

The authors wish to thank Professor David Hill for assistance with various aspects of this research.

\section{References}

[1] Devine, R. 2003. "Meat Consumption Trends in the World and the European Union." The National Institute of Agronomic Research, Livestock Production 16 (5): 325-327.

[2] Ministry of Agriculture and Fisheries. 2008. "Meat Consumption: Drop in Meat Consumption in 2008." Accessed January 22, 2009. http://www.agreste.agriculture.gouv.fr/img/syntheseviand e/id=0901.pdf.

[3] Ministry of Agriculture and Fisheries. 2009. "Meat Consumption: Meat Consumption is Still Contracting." Accessed November 13, 2009. http:// www.agreste.agriculture.gouv.fr/img/syntheseviande/id= 0910.pdf.

[4] Hocquette, J. F., Mainsant, P., Daudin, J. D., Cassar-Malek, I., Remond, D., and Doreau M. et al. 2013. "Will Meat be Produced in Vitro in the Future?" The National Institute of Agronomic Research, Livestock Production 26 (4): 363-374.

[5] Veissier, I., Sarignac, C., and Capdeville, J. 1999. "Methods to Assess the Welfare of Domestic Animals." The National Institute of Agronomic Research, Livestock Production 12 (2): 113-121.

[6] Veissier, I., Beaumont, C., and Levy, F. 2007. "'Research into Animal Welfare: Aims, Methods and Purpose." The National Institute of Agronomic Research, Livestock Production 20 (1): 3-10.

[7] Sonalya, E. B., and Swan, S. E. J. 2004. Small-Scale Poultry Production: Technical Guide. Rome, Italy: Animal Production and Health Division, FAO Edition.

[8] Kitalyi, A. J. 1998. Village Chicken Production Systems in Rural Africa: Household Security and Gender Issues. Rome, Italy: Animal Production and Health Division, FAO Edition.

[9] Kjaer, J. B., and Mench, J. A. 2003. "Behavior Problems Associated with Selection for Increased Production." In Poultry Breeding and Biotechnology, CAB International, 67-82.

[10] Dagnelie, P. 1986. Theories and Statistical Methods: Agronomic Applications. Belgium: Agronomic of Gembloux Press. 
[11] SAS Institute. 1990. SAS/STAT User's Guide, 4th Ed.. Cary, NC: SAS Institute.

[12] Buchan, G., Grewal, K. S., and Robson, A. B. 1993. "Improved Models of Particle Size Distribution: An Illustration of Model Comparison Techniques." Soil Science Society of American Journal 57: 901-908.

[13] Kern, J. S. 1995. "Evaluation of Soil Water Retention Models Based on Basic Soil Physical Properties." Soil Science Society of American Journal 59: 1134-1141.

[14] Tomassone, R. 1989. How to Interpret the Results of a Linear Regression? Paris: Technical Institute of Grain and Fodder Press.

[15] Younger, M. S. 1979. Handbook for Linear Regression. North Scituate, MA: Duxbury Press.

[16] Snedecor, G. W., and Cochran, W. G. 1980. Statistical Methods, 7th Edition. Ames, IA: Iowa State University Press.

[17] Freund, R. J., and Littell, R. C. 1986. SAS System for Linear Models, 1986 Edition. Cary, NC: SAS Institute Inc..

[18] Freund, R. J., Littell, R. C., and Spector, P. C. 1991. SAS System for Linear Models: Statistical Applications. Cary, NC: SAS Institute Inc..

[19] Tietje, O., and Hennings, V. 1996. "Accuracy of the Saturated Hydraulic Conductivity Prediction by Pedo-transfer Functions Compared to the Variability within FAO Textural Classes." Geoderma 69: 71-84.

[20] Perez, J. M., Ramihone, R., and Henry, Y. 1984. Prediction of the Energy Value of Compound Feeds for Swine: Experimantal Study. Versailles, Paris: The National Institute of Agronomic Research.

[21] Omoko, M. 2006. "Normal Agroclimatic Prediction Using Empirical Models." Tropicultura 24 (1): 19-24.

[22] Falconer, D. S. 1990. "Selection in Different Environments: Effects on Environmental Sensitivity (Reaction Norm) and on Mean Performance." Genetics Research 56: 87-60.

[23] Kolmodin, R., Strandberg, E., Jorjani, H., and Danell, B. 2002. "Selection in Presence of Genotype by Environment Interaction May Increase Environmental Sensivity." In Proceedings of the 7th World Congress of Genetic Application Livestock Production 33: 333-336.

[24] N'Dri, L. 2006. "Interaction between Genotype and Environment in Broilers and Lying Hens." Ph.D. thesis, Paris-Grignon Agronomy National Institute.

[25] Wagner, B., Tarnawski, V. R., Hennings, V., Müller, U., Wessolek, G., and Plagge, R. 2001. "Evaluation of Pedo-transfer Functions for Unsaturated Soil Hydraulic Conductivity Using an Independent Data Set." Geoderma 102: 275-297.

[26] Falconer, D. S. 1952. "The Problem of Environment and Selection." The American Naturalist 86: 293-293.
[27] Grossman, R. D. 1988. "Multiphasic Analysis of Growth Curves in Chicken." Poultry Science 67: 33-42.

[28] Wang, Z. Y., Chen, W. L., Bai, Q. A., Wang, J., and Wang, H. L. 2002. "The Compare Research on Growth Model of New Yangzhou Chickens." Heilongjiang Journal of Animal Science and Veterinary Medicine 12: 4-5.

[29] Zhang, L. 2002. "Studies on the Growth Traits of Minnan Turkey." Ecology of Domestic Animal 23: 27-29.

[30] Yang, H. M. X. Q., and Dai, G. J. 2004. "Analysis on Three Kinds of Growth Curve in Avian.” Chinese Poultry Science 8: 164-166.

[31] Zhang, H., Wu, C. X., Li, J. Y., and Ling Y. 2005. "Analysis of Fitting Growth Curve and Heterosis in Tibetan Chicken and Lowland Chicken Breeds." Chinese Journal of Animal Science 41: 34-37.

[32] Wei, F. S., Han, R. L., Kang, X. T., Shi, Z., Li, G. X., and Sun G. R. et al. 2005. "Analysis of Growth Curve in Gushi Chicken of Different Sex." Hennan Journal of Animal Science and Veterinary Medicine 26: 45-51.

[33] Wang, C. F., Zhang, L., Li, J. Y., and Wu, C. X. 2005. "Analysis of Body Conformation and Fitting Growth Model in Tibetan Chicken Raised in Plain." Scientia Agricultura Sinica 38: 1065-1068.

[34] Yang, Y., Mekki, D. M., Lv, S. J., Wang, L. Y., Yu, J. H., and Wang, J. Y. 2006. "Analysis of Fitting Growth Models in Jinhai Mixed-Sex Yellow Chicken." International Journal of Poultry Science 5 (6): 517-521.

[35] Alkan, S., Karabag, K., Galic, A., and Soner Balcioglu, M. 2008. "Predicting Yolk Height, Yolk Width, Albumen Length, Eggshell Weight, Egg Shape Index, Eggshell Thickness, Egg Surface Area of Japanese Quails Using Various Eggs Traits as Regressors." International Journal of Poultry Science 7 (1): 85-88.

[36] Farooq, M., Mian, M. A., Murad, A., Durrani, F. R., Asghar A., and Muqarrab, A. K. 2001. "Egg Traits of Fayumi Birds under Subtropical Conditions." Sarhad Journal of Agriculture 17: 141-145.

[37] Gul, N., Farooq, M., Durrani, F. R., Mian, M. A., Chand, N., and Ahmed, J. 2002. "Egg Traits and Hatching Performance of Non-descript Desi Chicken Produced under Backyard Conditions in District Charsadda." Journal of Animal and Veterinary Advances 1 (2): 58-60.

[38] Farooq, M., Gul, N., Chand, N., Durrani, F. R., Khurshid, A., and Ahmed, J. et al. 2002. "Production Performance of Backyard Chicken under the Care of Women in Charsadda, Pakistan." Livestock Research for Rural Development 14 (1): 27-34.

[39] Khurshid, A., Farooq, M., Durrani, F. R., Sarbiland, K., and Chand N. 2003. "Predicting Egg Weight, Shell Weight, Shell Thickness and Hatching Chick Weight of Japanese Quails Using Various Egg Traits as Regressors." 
International Journal of Poultry Science 2: 164-167.

[40] Ricard, F. H., Petitjean, M. J., Melin, J. M., Marche, G., and Malineau, G. 1991. "Growth and Fattening of Pheasants in Aviary or in Confinement." The National Institute of Agronomic Research, Livestock Production 4 (2): 117-121.

[41] Tor, M., Estany, J., Villalba, D., Molina, E., and Cublio, D. 2002. "Comparison of Carcass Composition by Parts and Tissues between Cocks and Capon." The National Institute of Agronomic Research, Livestock Production 51: 421-431.

[42] Leclercq, B. 1989. "Potential Leads and Interest Lean Genotypes in Poultry." The National Institute of
Agronomic Research, Livestock Production 2: 275-286.

[43] Süto, Z., Horn, P., Jensen, J. F., Sorensen, P., and Csapo, J. 1998. "Carcass Traits, Abdominal Fat Deposition and Chemical Composition of Commercial Meat Chicken during a Twenty Week Growing Period." Archiv. for Geflügelkunde 62: 21-25.

[44] Griffin, H. D., Guo, K., Windsor, D., and Butterwith, S. C. 1992. "Adipose Tissue Lipogenesis and Fat Deposition in Leaner Broiler Chickens." Journal of Nutrition 122: 363-368.

[45] Belabbas, H. 2007. "Bodies of Growth Momentum in Broiler Chickens." Master thesis, El-Hadj Lakhdar University. 